\title{
Hemodynamic Response to Thoracoscopy and Thoracotomy
}

\author{
S. TRČA ${ }^{1}$, Z. KRŠKA ${ }^{1}$, O. KITTNAR ${ }^{2}$, M. MLČEK ${ }^{2}$, R. DEMES̆ ${ }^{1}$, V. DANZIG ${ }^{3}$, S. S̆IMEK $^{3}$, \\ J. BRUTHANS ${ }^{4}$, R. FRAŠKO ${ }^{1}$
}

${ }^{1}$ First Surgical Department, Clinical Department of Abdominal, Thoracic Surgery and

Traumatology of the First Faculty of Medicine and General Teaching Hospital, Charles University, Prague, ${ }^{2}$ Institute of Physiology, First Faculty of Medicine, Charles University, Prague,${ }^{3}$ Second Medical Department, Clinical Department of Cardiology and Angiology, First Faculty of Medicine and General Teaching Hospital, Charles University, Prague, ${ }^{4}$ Department of Anesthesiology and Resuscitation, First Faculty of Medicine and General Teaching Hospital, Charles University, Prague, Czech Republic

Received January 23, 2009

Accepted June 3, 2009

On-line August 12, 2009

\section{Summary}

Operations in the pleural cavity are connected with circulatory changes in pulmonary circulation and general changes of hemodynamics. These changes are influenced by the position of patient's body on the operation table and by the introduction of artificial pneumothorax. Thoracoscopy is an advanced surgical approach in thoracic surgery, but its hemodynamic effect is still not known. The aim of the present study was to compare the hemodynamic response to surgeries carried out by open (thoracotomy - TT) and closed (thoracoscopy - TS) surgical approach. Thirty-eight patients have been monitored throughout the operation - from the introduction of anesthesia to completing the surgery. Monitored parameters were systolic blood pressure (BPs), diastolic blood pressure (BPd), $\mathrm{O}_{2}$ saturation $\left(\mathrm{SaO}_{2}\right)$, systolic blood pressure in pulmonary artery (BPPAs), diastolic blood pressure in pulmonary artery (BPPAd), wedge pressure $\left(P_{W}\right)$, central venous pressure in right atrium (CVP), cardiac output (CO) and total peripheral resistance (TPR). No significant difference has been found in hemodynamic response between $T T$ and TS groups. Significant changes of hemodynamic parameters occurring during the whole surgical procedure were detected in both technical approaches. The most prominent changes were found after the position of patients was changed to the hip position (significantly decreased $\mathrm{BPs}, \mathrm{BPd}, \mathrm{MAP}, \mathrm{SaO}_{2}$ and BPPAs) and 5 min after the pneumothorax was established (restoration of the cardiac output to the initial value and significant decrease of the TPR). It can be concluded that the thoracoscopy causes almost identical hemodynamic changes like the thoracotomy.

\section{Key words}

Hemodynamics • Pulmonary circulation • Thoracoscopy • Thoracotomy

\section{Corresponding author}

Otomar Kittnar, Institute of Physiology, $1^{\text {st }}$ Medical Faculty, Charles University, Albertov 5, 12800 Prague 2, Czech Republic. E-mail: okittnar@lf1.cuni.cz

\section{Introduction}

There are numerous reports about hemodynamic changes during the operation in pleural cavity (Hill et al. 1996, Jones et al. 1993, Ohtsuka et al. 1999, Polis et al. 2002, Vassiliades 2002, Ohtsuka et al. 2001). Lowpressure pulmonary circulation may serve as a blood reservoir due to its substantive capacity. A short-term increase of blood volume in pulmonary circulation causes dilatation of pulmonary vessels, but the blood pressure in this region increases only moderately. Thus the pulmonary circulation may be engaged as a quasi-buffer system during short-term vacillation in blood volume. First changes in pulmonary circulation occur already in the introduction to anesthesia, when the patient is positioned on the back and anesthetics are administered (Ohtsuka et al. 1999, Brock et al. 2000, Zobel et al. 1994, Forlanini 1988). 
Table 1. Patients involved in the study.

\begin{tabular}{lcccccc}
\hline \multirow{2}{*}{ GROUP } & \multicolumn{3}{c}{ THORACOTOMY } & \multicolumn{3}{c}{ THORACOSCOPY } \\
& Total & Men & Women & Total & Men & Women \\
\hline $\begin{array}{l}\text { Numbers } \\
\text { Age-mean (range) }\end{array}$ & 19 & 16 & 3 & 19 & 13 & 6 \\
ASSOCIATED DISEASES: & & $58(33-68)$ & & & $41(19-68)$ & \\
COBD & & & & & & \\
IHD & 2 & 2 & 0 & 2 & 1 & 1 \\
Diabetes & 5 & 4 & 1 & 3 & 3 & 0 \\
Arterial hypertension & 4 & 4 & 0 & 2 & 1 & 1 \\
PREVIOUS THORACIC SURGERY: & 5 & 3 & 2 & 1 & 1 & 0 \\
Numbers & & & & & & \\
PREVIOUS NON-THORACIC SURGERY: & 0 & 0 & 0 & 0 & 0 & 0 \\
Appendectomy & & & & & & \\
Cholecystectomy & 1 & 1 & 0 & 3 & 3 & 3 \\
\hline
\end{tabular}

COBD - chronic obstructive broncho-pulmonary disease, IHD - ischemic heart disease.

Further hemodynamic changes occur during the hip placement (Brock et al. 2000, Forlanini 1988). In this position, and after the surgical table is repositioned, the mean blood pressure increases in vessels below the pulmonary valve due to increment of hydrostatic pressure while in regions above the valve the pressure simultaneously diminishes. The pressure might be even negative in comparison to a pressure in alveoli in these regions. It logically results in decreased alveolar perfusion as the alveolar pressure compresses the capillaries. In extreme situations, the partial respiratory gas pressures could be altered in well-ventilated but nonperfused alveoli (Ohtsuka et al. 2001, Brock et al. 2000, McFaden and Robbins 1998, Mack 1993).

Next, the situation is changed by accomplishing of the artificial pneumothorax as partial gas pressures in the alveoli of non-ventilated but well perfused lung are starting to change. Partial pressures of $\mathrm{O}_{2}$ decrease, while partial pressures of $\mathrm{CO}_{2}$ increase. Ventilation changes induced by pneumothorax influence ventilation/perfusion ratio. Functional perfusion shunt occurs in non-ventilated lung. The hemodynamics is also influenced by metabolic functions of lungs (Vassiliades 2002, McFaden and Robbins 1998, Mack 1993, Kvasnicka et al. 1998, Vokurka 2003, Čiernik and Vokurka 2006).

As mentioned above, changes in hemodynamics caused by a surgery in the pleural cavity are well known. There is, however, lack of information on the hemodynamics during thoracoscopic procedures and that is why this study was designed to clear up if any difference in hemodynamic response between two groups of patients occurs - one group operated via posterolateral thoracotomy, the other one just thoracoscopied (Pafko et al. 1998).

\section{Methods and patients}

In total, 38 patients have been involved in prospective non randomized study - 19 undergoing thoracotomy (TT), 19 thoracoscopy (TS) (Table 1). All of them underwent a surgery in the First Surgical Department of General Teaching Hospital and the First Faculty of Medicine, Charles University, Prague. The study was approved by the ethic committee; all patients signed an informed consent.

In order to obtain homogenous set of patients only those with NYHA I or II were included, the exclusion criteria were significant valve defects, left ventricle failure, primary or secondary pulmonary hypertension.

Pulmonary artery catheter (Corodyn P1, B. Braun) was placed 2 to 16 hours prior to the operation under X-ray control in the non-operated lung. Before the first measurement, blood clotting was prevented with continuously administered heparin. Deep vein thrombosis was prevented with low-molecular heparin in routine prophylactic dose, for the first time administered after the catheter was inserted. In order to gain the most accurate 
record, all the measurements were repeated three times in two-minute intervals.

All patients of both groups underwent the surgery in a total anesthesia. For all of them a selective lung ventilation was used with a possibility to ventilate only one lung. Patients who were planned for thoracotomic procedure received an epidural analgesic catheter immediately in preoperative period.

In both groups of patients a wide range of operating procedures was performed. Namely, the procedures included: 1) in the TS group: simple diagnostic thoracoscopies, and pleurodeses for pulmonary emphysema and spontaneous pneumothorax, 2) in the TT group: non-anatomic lung resections, resections of bullae, anatomic lung resections (lobectomy). The patients could not be randomized for ethic reasons as the surgical approach (TS or TT) had to be chosen according to a type of surgical procedure.

The 11 consecutive measurements were accomplished in an operating theatre in the both groups in the following pattern:

$1^{\text {st }}$ measurement: in the position on the back before any anesthesia was administered,

$2^{\text {nd }}$ measurement: in the same position after the introduction to anesthesia and intubation (both lungs were ventilated),

$3^{\text {rd }}$ measurement: in the same position (only the nonoperated lung ventilated),

$4^{\text {th }}$ measurement: in the hip position (the patient lies with the underpinned chest on an operating table on a contralateral side to that where an operation is conducted),

$5^{\text {th }}$ measurement: in the same position just after the pneumothorax was established,

$6^{\text {th }}$ measurement: in the same position 5 min after the pneumothorax was established,

$7^{\text {th }}$ to $10^{\text {th }}$ measurements: in the same position, each measurement performed 15 minutes after the previous,

$11^{\text {th }}$ measurement: in the same position after the operated lung was unfolded and both lungs were ventilated again.

Following parameters were recorded: systolic blood pressure (BPs), diastolic blood pressure (BPd) and mean arterial pressure (MAP) - all of them by the invasive approach (Arteriofix B. Braun), $\mathrm{O}_{2}$ saturation $\left(\mathrm{SaO}_{2}\right)$ - pulse oximetry (RAD-5, Masimo Corp. USA), systolic blood pressure in pulmonary artery (BPPAs), diastolic blood pressure in pulmonary artery (BPPAd), wedge pressure $\left(\mathrm{P}_{\mathrm{W}}\right)$, central venous pressure in right atrium (CVP) - all of them invasive approach (Corodyn $\mathrm{P} 1$, B. Braun), and cardiac output (CO) ultrasonography, esophageal probe (PEF-510MA, Nemio SSA-550A Toshiba Medical Systems). Total peripheral resistance (TPR) was calculated using the formula TPR = MAP / CO.

Each final value was computed as the arithmetic mean from the three measured values as all the measurements were repeated three times (as mentioned above). For a statistic evaluation the T-test for two independent statistical samples was used.

\section{Results}

The changes of hemodynamic parameters during the whole surgical procedure (Figs 1, 2, 3 and 4)

There were only subtle changes in the lowpressure circulation, where we have found a significant decrease of the BPPAs after the position of patients was changed to the hip position and increase of both BPPAs and BPPAd after the pneumothorax was established.

While the low-pressure circulation is relatively stable during the whole surgical procedure, there are dramatic changes in the high-pressure circulation. We have found a significant decrease in blood pressure (BPs, BPd and MAP) after the position of patients was changed to the hip position followed by immediate increase to the initial values. Next decrease was detected $20 \mathrm{~min}$ after establishing of the pneumothorax. The cardiac output has decreased after anesthesia was administered and it was impaired until the 5th minute after establishing of the pneumothorax. Even more pronounced changes almost reverse to those of the $\mathrm{CO}$ were found in the TPR. The $\mathrm{SaO}_{2}$ was increased after anesthesia was administered while a significant decrease of the $\mathrm{SaO}_{2}$ was found in the 5 th minute after establishing of the pneumothorax.

\section{Significant differences between both procedures} (thoracotomy vs. thoracoscopy) (Fig. 5)

Wedge pressure $(\mathrm{Pw})$ was significantly higher in thoracotomy in the $2^{\text {nd }}$ measurement (when both lungs are ventilated). $\mathrm{CO}$ wais significantly higher in thoracotomy in the $3^{\text {rd }}$ measurement (when non-operated lung is ventilated). TPR was significantly higher in thoracotomy in the $1^{\text {st }}$ measurement (before anesthesia) and lower in the $5^{\text {th }}$ measurement (after the pneumothorax was established) and $11^{\text {th }}$ measurement (after the operated lung was unfolded and both lungs were ventilated again). 

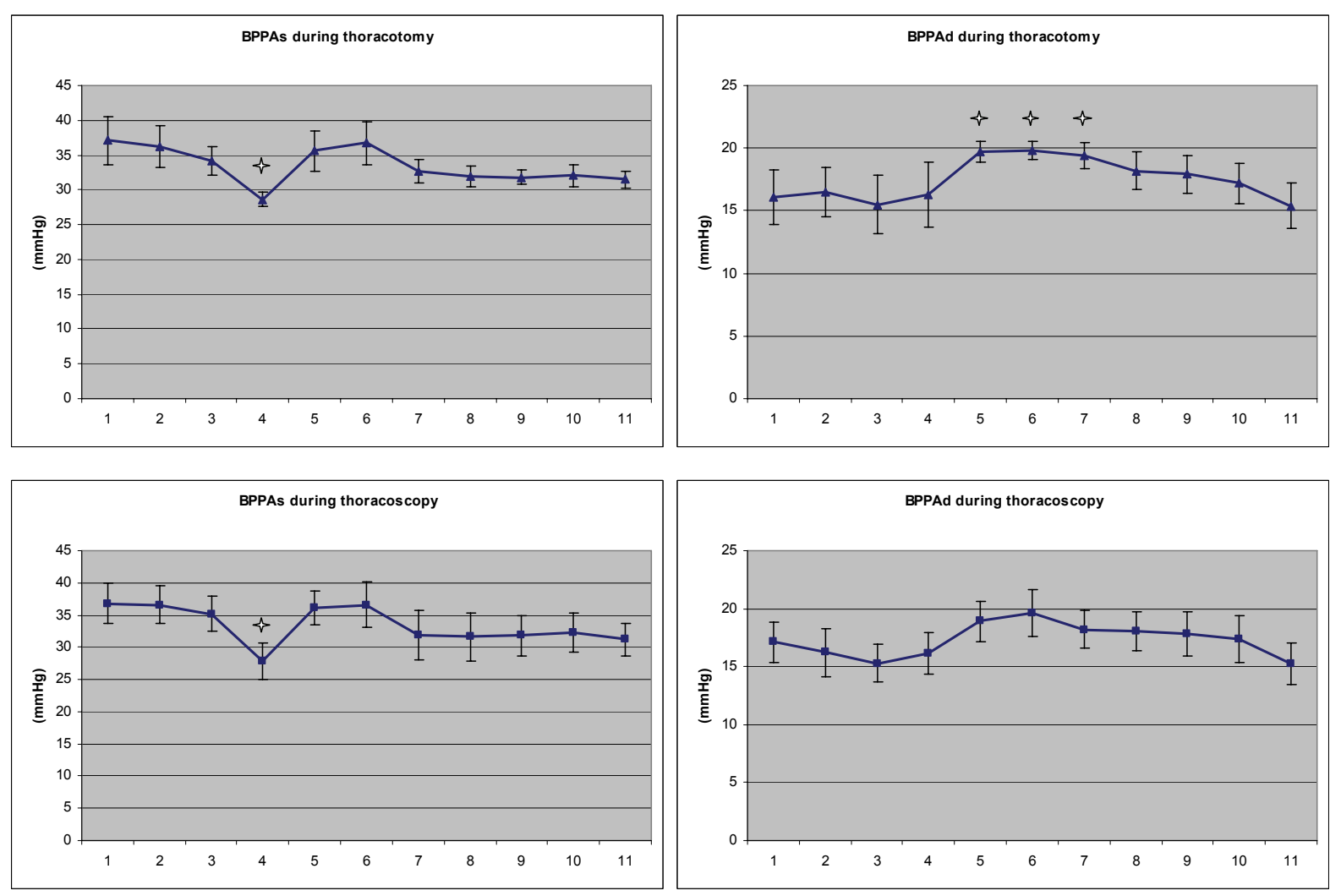

Fig. 1. The changes of systolic blood pressure in pulmonary artery (BPPAs) and diastolic blood pressure in pulmonary artery (BPPAd) during the whole surgical procedure in both technical approaches (statistically significant differences $-p<0.05-$ from the first measurement are indicated by stars). For numbers of measurements (abscissa) see Methods.
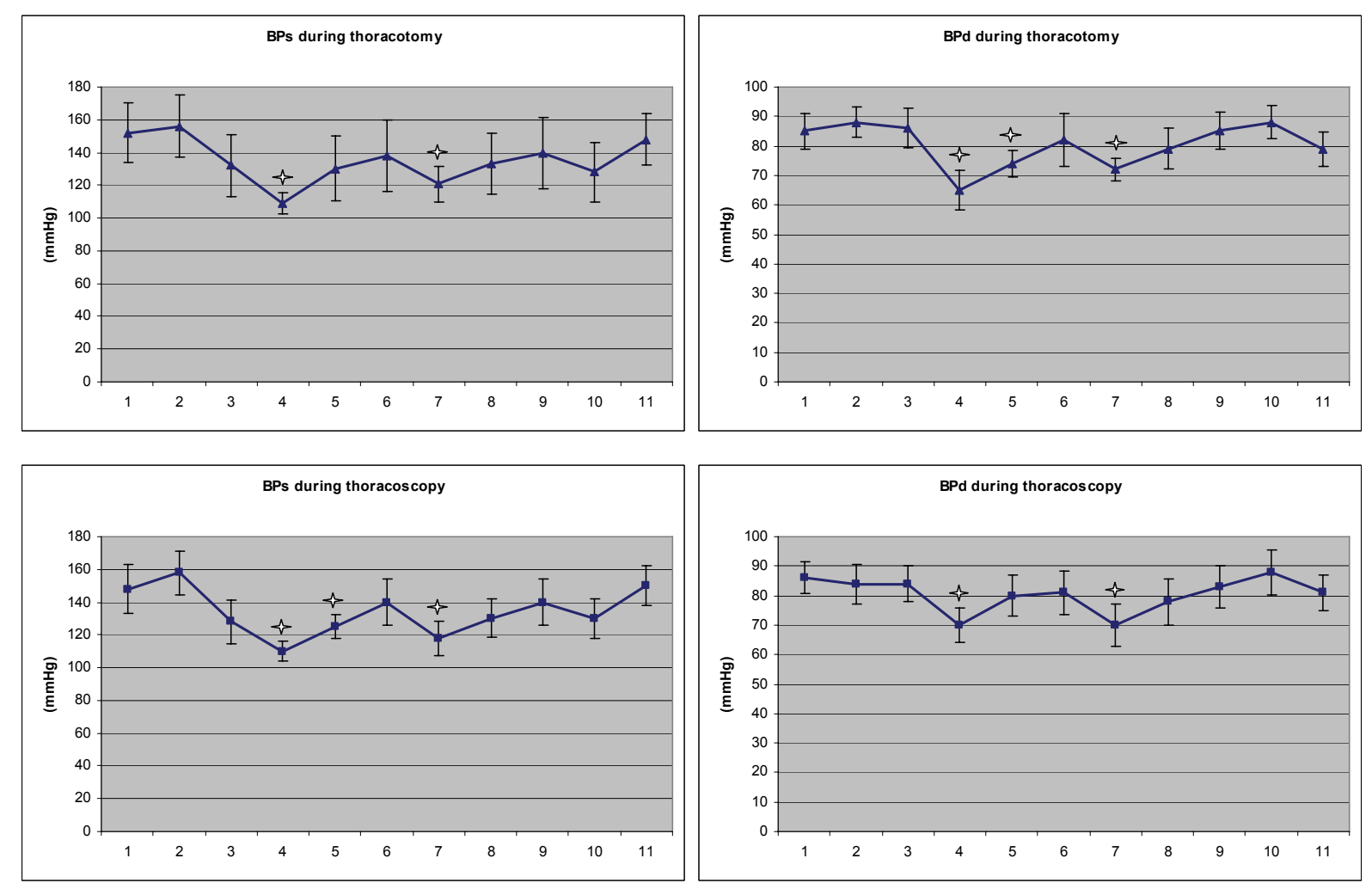

Fig. 2. The changes of systolic blood pressure (BPs) and diastolic blood pressure (BPd) during the whole surgical procedure in both technical approaches (statistically significant differences from the first measurement are indicated by stars). The numbers of measurements (abscissa) are identical with those on the Fig. 1. 

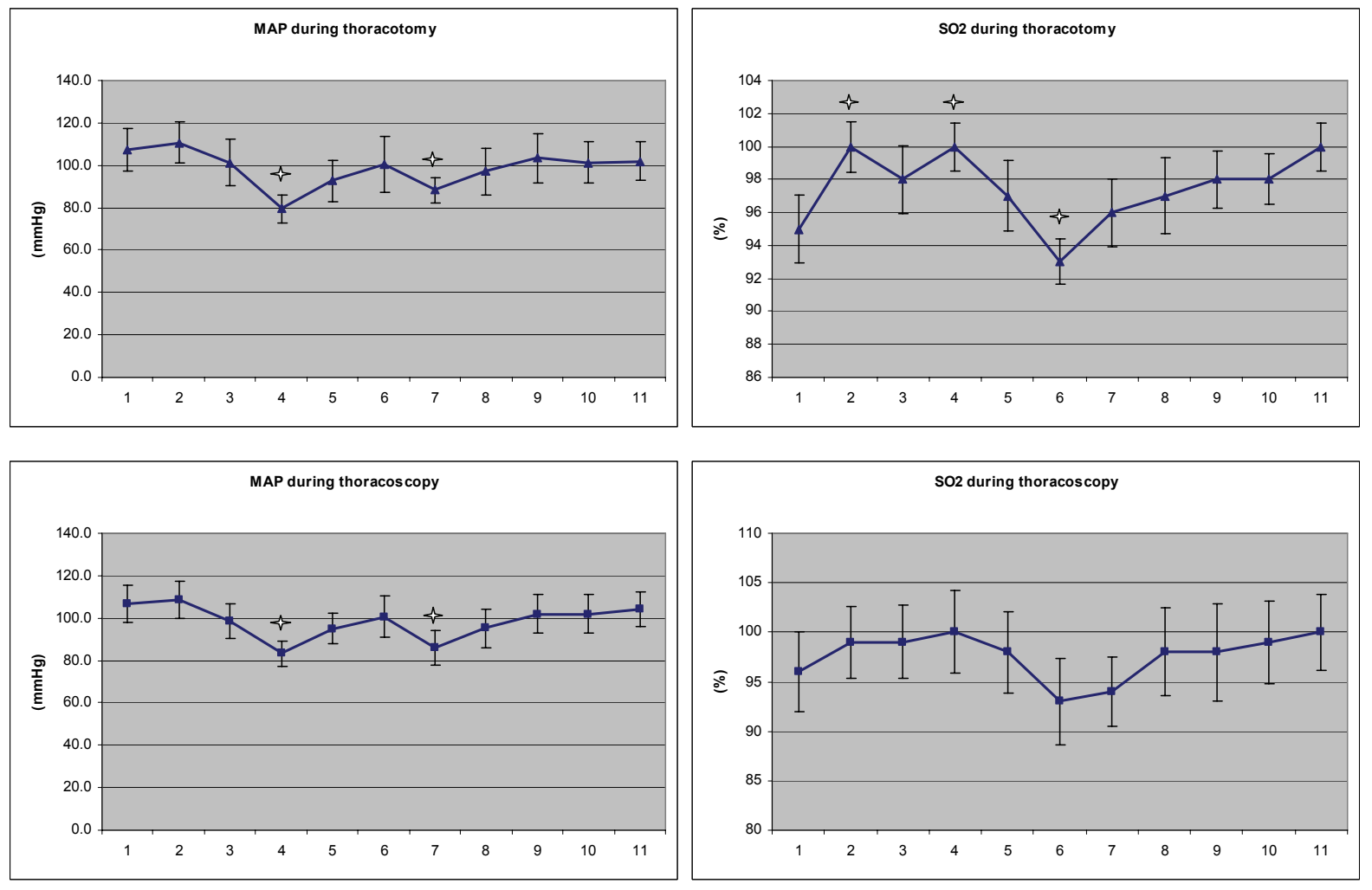

Fig. 3. The changes of mean arterial pressure (MAP) and $\mathrm{O}_{2}$ saturation $\left(\mathrm{SaO}_{2}\right)$ during the whole surgical procedure in both technical approaches (statistically significant differences from the first measurement are indicated by stars). The numbers of measurements (abscissa) are identical with those on the Fig. 1.
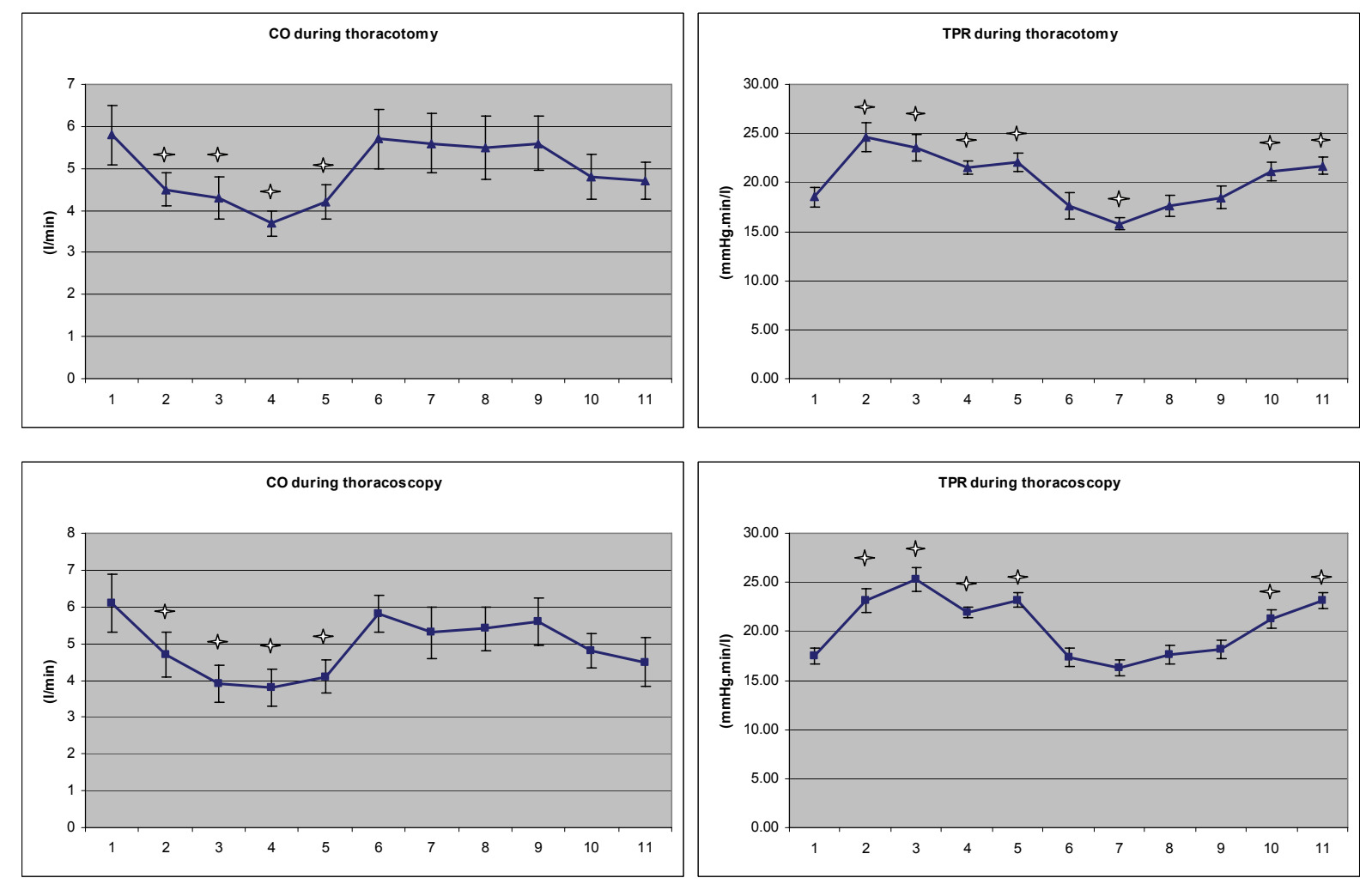

Fig. 4. The changes of cardiac output (CO) and total peripheral resistance (TPR) during the whole surgical procedure in both technical approaches (statistically significant differences from the first measurement are indicated by stars). The numbers of measurements (abscissa) are identical with those on the Fig. 1. 

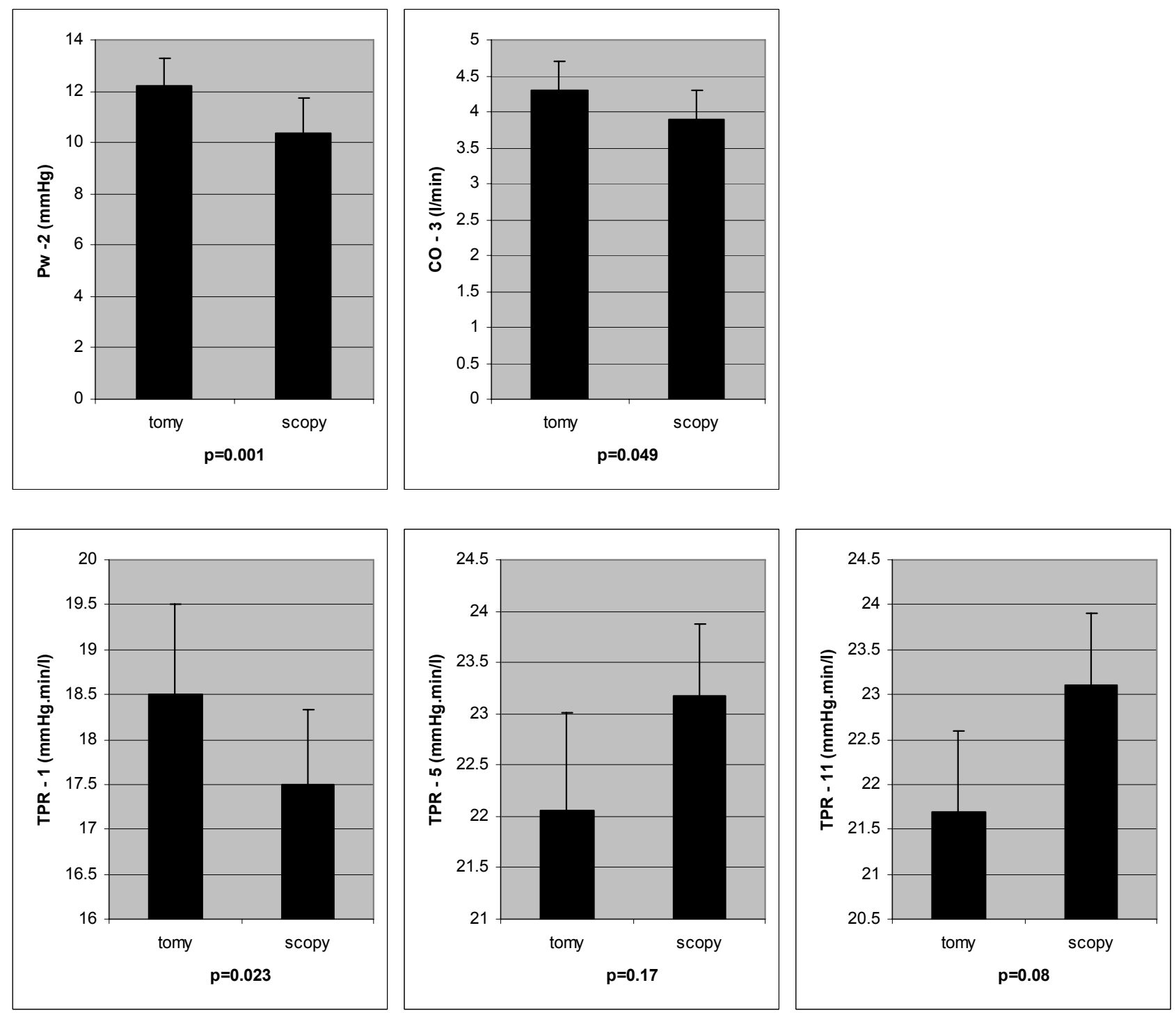

Fig. 5. Significant differences between both procedures (thoracotomy vs. thoracoscopy): wedge pressure (Pw) in the $2^{\text {nd }}$ measurement, cardiac output (CO) in the $3^{\text {rd }}$ measurement, total peripheral resistance (TPR) in the $1^{\text {st }}, 5^{\text {th }}$ measurement and $11^{\text {th }}$ measurement.

No significant differences have been found in any of the BPs, BPPAs or CVP measurements.

Only minor and presumably unrelated differences in other variables ( $\mathrm{BPd}, \mathrm{SaO}_{2}$, and BPPAd) have been found. Therefore, there is no indication of different hemodynamic load during thoracotomy and thoracoscopy.

\section{Discussion}

Our working hypothesis that the two surgical approaches (thoracotomy vs. thoracoscopy) lead to similar circulatory changes was confirmed. Peroperative changes are almost identical in both groups. Some differences could be expected in the postoperative period, at the time of healing and recovery.
Optimization of operational techniques in thoracic surgery aims to positively affect post-operative state and to reduce potential complications which can occur particularly in older patients with co-morbidity or in altered patients. Complex surveillance of tissue and organ response epitomizes a possibility how to evaluate theoretical models in clinical setting with a high clinical significance (Kvasnička et al. 1998, Goris and Trentz 1995, Šiller and Havlíček 2004, Bříza et al. 2002).

Both approaches to operation in pleural cavity require adequate (and for both the same) position on the operation table, and also the selective ventilation of both lungs in order to enable a surgery on collapsed lung. Usually, there is no analogy to laparoscopy that is miniinvasive endoscopy in abdominal cavity, where overpressure is needed. This contributes to pressure 
changes and therefore to changes in circulation in central veins (Goris and Trentz 1995, Šiller and Havlíček 2004, Čiernik and Vokurka 2006, Andrus 1994). Such a capnopleural overpressure can be used, when collapse of pleural parenchyma is limited. In our groups this technique was not used, because it significantly influences hemodynamics as was previously demonstrated (Demes et al. 2001).

As the overpressure technique is not generally used, we do not have to consider circulatory changes in the area of semi-rigid thoracic wall and elastic lungs. The question of mediators release resulting in the tissue response apparently does not affect the immediate postoperation period.

In recent 10 years some controversial findings were reported for hemodynamic effects of $\mathrm{CO}_{2}$ insufflation during thoracoscopy particularly when combined with changes in patient position (Vitali et al. 2000, Byhahn et al. 2001, Tomescu et al. 2007), but it seems to be more obvious now that these changes are not significant. Our findings support this conclusion and they demonstrate that no adverse hemodynamic effects appear during a more invasive procedure, i.e. thoracotomy. Only very small differences were found when only one lung was ventilated (increased CO) in spite of fact that one-lung ventilation increases mechanical stress in the lung and affects not only ventilation but also perfusion and thus it can theoretically also affect hemodynamic parameters.

As for the changes of hemodynamic parameters during the whole surgical procedure it needs to be emphasized that both operating techniques can result in major hemodynamic changes. These changes are most pronounced when a patient is placed in a lateral hip position, at the time when unilateral lung ventilation is being started and at the time when we create an artificial pneumothorax.

According to our measurements, placement of a patient on his/her side had the major impact on the hemodynamic changes. In that moment, we recorded a decrease of both systolic and diastolic blood pressure and a decrease of the systolic pressure in the pulmonary artery. The cardiac output declined and the total peripheral resistance increased after the induction of anesthesia. We consider these changes to be a sign of circulatory subcompensation resulting from decreased venous return, altered blood pressure, mediastinal shift after opening of pleural cavity and overall increase of peripheral vascular resistance. Our further results do not show such considerable changes as at the time of artificial pneumothorax accomplishing. We suppose that a decrease of the peripheral resistance after accomplishing of the artificial pneumothorax has resulted in the restoration of the cardiac output. We think that an appropriate anesthesia and our effort to prevent more pronounced hemodynamic changes have prevented subsequent hemodynamic deterioration. Oxygen saturation has been increasing after the induction of anesthesia and was decreasing after creation of artificial pneumothorax. These findings could be explained by the fact that artificial ventilation closes arterio-venous shunts in a non-ventilated lung what is quite opposite situation in comparison to a spontaneous ventilation.

The sporadic differences between both surgical approaches (TT vs. TS) were detected only at the beginning of the operations ( $\mathrm{PW}$ in the second measurement, $\mathrm{CO}$ in the third measurement and TPR already in the first measurement). These changes could be at least partially explained by an epidural analgesic catheter that was implemented to the TT patients in a preoperative period.

Results of the study have fully confirmed our working hypothesis. Peroperative response does not depend on the type of surgical approach (TT vs. TS), it is dependent on the position of the patients body (back vs. hip position) and performed procedures (anesthesia, pneumothorax). Moreover, it can depend on the severity of underlying disease and presumably on the extent of surgical performance (simple thoracoscopy, pleurodesis, small anatomic and non-anatomic lung resection vs. large anatomic lung resection - pneumonectomy). Available papers did not yet compare both surgical approaches (TT vs. TS). Results of monitoring during the operating performance (TT) are consistent with published studies (Ohtsuka et al. 1999, Brock et al. 2000, Zobel et al. 1994, Forlanini 1988).

\section{Conclusions}

According to evaluated data, we have not found any difference in hemodynamic response between the two methods - thoracotomy and thoracoscopy - but significant changes of hemodynamic parameters during the whole surgical procedure almost identical in both technical approaches. It means that thoracoscopy causes the same hemodynamic changes like thoracotomy does. From clinical point of view the choice of a surgical 
approach (TT vs. TS) has to be done just according to the extent of the planned surgery without any regards to the hemodynamic processes in the body.

\section{Conflict of Interest}

There is no conflict of interest.

\section{Acknowledgements}

This work was supported by grant IGA MZ CR 8830-4.

\section{References}

ANDRUS CH: Anesthetic and physiological changes during laparoscopy and thoracoscopy. The surgeon's view. Semin Laparosc Surg 1: 228-240, 1994.

BŘÍZA J, KUDRNA K, KVASNIČKA J, BUŠTA O, TRČA S: Acute phase reactions in severe injuries (in Czech). Sbk Lek 103: 193-202, 2002.

BROCK H, RIEGER R, GABRIEL C, POLZ W, MOOSBAUER W, NECEK S: Haemodynamic changes during thoracoscopic surgery the effects of one-lung ventilation compared with carbon dioxide insufflation. Anaesthesia 55: 10-16, 2000.

BYHAHN C, MIERDL S, MEININGER D, WIMMER-GREINECKER G, MATHEIS G, WESTPHAL K: Hemodynamics and gas exchange during carbon dioxide insufflation for totally endoscopic coronary artery bypass grafting. Ann Thorac Surg 71: 1496-1501, 2001.

ČIERNIK J, VOKURKA J: Surgical procedures in patients after heart transplantation - a retrospective study. Scripta Med 79: 93-98, 2006.

DEMES R, CERMAK S, VYBORNY J, PESKOVA M, ZEMAN M, KRSKA Z, REHAK M, TRCA S, PAUL O: Videothoracoscopy and video-assisted surgical procedures in penetrating injuries of the thorax (in Czech). Rozhl Chir 80: 304-307, 2001.

FORLANINI C: A contribuzioni della terapeutica chirurgica della tisi - Ablazione del polmone? Pneumotorace artificiale. GazzOsp 2, 3, 68: 573-579, 585-587, 1988.

GORIS RJA, TRENTZ O: The Integrated Approach to Trauma Care. The First 24 Hours. Springer, Berlin, 1995, $272 \mathrm{pp}$.

HILL RC, JONES DR, VANCE RA, KALANTARIAN B: Selective lung ventilation during thoracoscopy: effects of insufflation on hemodynamics. Ann Thorac Surg 61: 945-948, 1996.

JONES DR, GRAEBER GM, TANGUILIG GG, HOBBS G, MURRAY GF: Effects of insufflation on hemodynamics during thoracoscopy. Ann Thorac Surg 55: 1379-1382, 1993.

KVASNIČKA J, BŘÍZA J, KRŠKA Z, KUDRNA K, PEŠKOVÁ M, PECEN L: Increase of soluble cytoadhesive molecules sE-selectin and sICAM-1 and hyperfibrinogenaemia in patients with polytrauma without septicaemia (in Czech). Sb Lek 99: 93-96, 1998.

MACK JM: The First International Symposium on Thoracoscopic Surgery San Antonio, Texas, January 22-23, 1993. Ann Thorac Surg 56: 3, 1993.

MCFADEN PM, ROBBINS RJ: Thoracoscopic surgery. Surg Clin N Amer 78: 763-794, 1998.

OHTSUKA T, IMANAKA K, ENDOH M, KOHNO T, NAKAJIMA J, KOTSUKA Y, TAKAMOTO S: Hemodynamic effects of carbon dioxide insufflation under single-lung ventilation during thoracoscopy. Ann Thorac Surg 68: 29-32, discussion 32-33, 1999.

OHTSUKA T, NAKAJIMA J, KOTSUKA Y, TAKAMOTO S: Hemodynamic responses to intrapleural insufflation with hemipulmonary collapse. Surg Endosc 15: 1327-1330, 2001.

PAFKO P (ed): Laparoscopic and thoracoscopic surgery in practice (in Czech). Grada Publishing, Praha, 1998, 106 pp.

POLIS I, GASTHUYS F, GIELEN I, VAN RYSSEN B, VAN BREE H, LAEVENS H, DE RIJCKE L: The effects of intrathoracic pressure during continuous two-lung ventilation for thoracoscopy on the cardiorespiratory parameters in sevoflurane anaesthetized dogs. J Vet Med A Physiol Pathol Clin Med Apr 49: 113-120, 2002.

ŠILLER J, HAVLÍČEK K: Postoperative pulmonary complications following lung resection (in Czech). Slov Chir 1: 9-14, 2004. 
TOMESCU D, GRIGORESCU B, NITULESCU R, TOMULESCU V, POPESCU I, TULBURE D: Hemodynamic changes induced by positive pressure capnothorax during thoracoscopic thymectomy. Chirurgia 102: 263-270, 2007.

VASSILIADES TA: The cardiopulmonary effects of single-lung ventilation and carbon dioxide insufflation during thoracoscopic internal mammary artery harvesting. Heart Surg Forum 5: 22-24, 2002.

VITALI RM, REDDY RC, MOLINARO PJ, SABADO MF, JACOBOWITZ IJ: Hemodynamic effects of carbon dioxide insufflation during endoscopic vein harvesting. Ann Thorac Surg 70: 1098-1099, 2000.

VOKURKA J: Influence of electric current on liver parenchyma of the rat. Acta Vet 72: 547-551, 2003.

ZOBEL G, DACAR D, RODL S: Hemodynamic effects of different modes of mechanical ventilation in acute cardiac and pulmonary failure: an experimental study. Crit Care Med 22: 1624-1630, 1994. 